\title{
Analisa Pengunaan dan Produktivitas Alat Berat pada Kegiatan Peningkatan Ruas Jalan Simpang Pauh - Air Hitam Provinsi Jambi
}

\author{
Fadhilah Akbar, Fakhrul Rozi Yamali*, Annisaa Dwiretnani \\ Program Studi Teknik Sipil Universitas Batanghari Jambi \\ *Correspondence email: fakhrul_65@yahoo.co.id
}

\begin{abstract}
Abstrak. Dalam suatu pekerjaan perbaikan ruas jalan simpang pauh - air hitam memiliki suatu kendala dalam mengadakan alat berat dengan lamanya umur alat berat yang digunakan dalam melakukan penaspalan yang terlalu membutuhkan waktu, dikarenakan dalam suatu pemilihan jenis dan tahun alat berta yang digunakan merupakan jenis alat berat dengan tahun lama makan produktivitas yang timbul pada alat berat merupakan salah satu faktor yang sangat penting dalam menentukan suatu keberhasilan dalam mejalankan kegiatan konstruksi agar sesuai dengan jadwal yang telah direncanakan maka waktu proses pekerjaan alat berat sangat berpengaruh penting dalam perhitungkan supaya untuk mengetahui kerja alat sesuai dengan jadwal yang telah dibuat dan dapat megurangi keterlambatan dalam suatu pekerjaan konstruksi. Dari hasil analisa diperoleh hasil perhitung Produktivitas Asphalt Finisher merk Mitsubishi MF40W didapat sebesar 39, 68 Ton/jam, produktivitas Tandem Roller Lutong Ltc didapat sebesar 38,03 Ton/Jam, dan Produktivitas Pneumatic Tired Roler KR20W didapat sebesar 37, 56 Ton/Jam dengan volume pekerjan 1450,04 Ton membutuhkan lama waktu pekerjaan masing - masing alat selama 6 hari, sedangkan untuk perbandingan dengan alat baru memperoleh hasil perhitungan Produktivitas Asphalt Finisher merk Vollvo P2820D Tahun 2020 didapat sebesar 69,58 Ton/Jam, Tandem Roller merk Vollvo DD 105 Tahun 2020 didapat sebesar 83,38 Ton/Jam, dan Pneumatic Tired Roller merk Vollvo PT220 Tahun 2020 didapat sebesar 82,56 Ton/Jam dengan lama pekerjaan 3 hari.
\end{abstract}

Kata kunci: Peningkatan ruas jalan; Time schedule; dan Analisa Produktivitas alat berat.

\section{PENDAHULUAN}

Dalam melakukan suatu pekerjaan peningkatan ruas jalan simpang pauh kecamatan air hitam kabupaten sarolangun memiliki masalah tehadap alat berat yang digunakan di lapangan makan produktivitas alat sangan menunjang untuk kelberhailan dalam melakukan pekerjaan tersebut.

Maksud tujuan dari perhitungan produktivitsa alat berat adalah untuk mengetahui apakah alat berat yang digunakan merupakan alat berat yang layak atau tidak dalam melakukan pekerjaan dilapangan agar dapat menunjang hasil kerja yang baik dan efisien.

\section{Landasan Teori}

\section{Produktivitas alat berat}

Dalam melakukan perhitungan produktifitas alat berat ini merupakan analisa terhadap peralatan yang digunakan di lapangan untuk melaksanakan suatu kegiatan yang dilaksnakan oloh alat bantu untuk tenaga kerja di lapangan agar dapat mempermudah pekerjaan.

\section{Koordinasi alat - alat yang digunakan}

\section{Asphalt finisher}

Kapasitas alat Asphalt Finisher dinyatakan dengan rumus berikut:

$\mathrm{Qaf}=(\mathrm{W} \times \mathrm{S} \times 60 \times \mathrm{E} \times \mathrm{P} \times \mathrm{D} 1)$

Keterangan :

Qaf = Produktifitas Alat Berat Asphalt Finisher

$\mathrm{W}=$ Lebar Suatu Hamparan

$\mathrm{S}=$ Kecepatan Alat Berat

$\mathrm{E}=$ Efesiensi Alat Berat

$\mathrm{P}=$ Tebal Suatu Hamparan

DI $=$ Berat Jenis Aspal

\section{Tandem Roller}

Kapasitas alat Tandem Roller dinyatakan dengan rumus seperti di bawah ini.

$Q t d=\frac{\text { Wx Sx Px EX x DI }}{\mathrm{N}}$

Keterangan :

Qtd = Produktifitas Alat Berat Tandem Roller

$\mathrm{W}=$ Lebar Pengilasan Alat Berat 
Fadhilah Akbar, Fakhrul Rozi Yamali dan Annisaa Dwiretnani, Analisa Pengunaan dan Produktivitas Alat Berat pada Kegiatan Peningkatan Ruas Jalan Simpang Pauh - Air Hitam Provinsi Jambi

$\mathrm{S}=$ Kecepatan Gerak Alat Berat

$\mathrm{E}=$ Efesiensi Pekerjaan Pada Alat

$\mathrm{N}=$ Laju Bolak Balik Suatau Alat Berat

$\mathrm{P}=$ Tebal Pemadatan Oleh Alat Berat

\section{Pneumatic tired Roller}

Kapasitas alat pneumatic tired roller dinyatakan dengan rumus berikut:

Qptr $=\frac{\text { Wx Sx Px EXx DI }}{\mathrm{N}}$

Keterangan :

Qptr $=$ Produktifitas Pekrjaan Alat pneumatic Tyred Roller

$\mathrm{S}=$ Kecepatan Laju Alat Berat

$\mathrm{E}=$ Efesiensi Pekerjaan Alat Berat

$\mathrm{N}=$ Jumlah Bolak Balik Alat Berat

$\mathrm{P}=$ Tebal Suatu Pemadatan Alat Berat

$\mathrm{DI}=$ Berat Jenis aspal

\section{Efesiensi alat berat}

Produktivitas alat berat dalam suatu pekerjaan dipengaruhi beberapa faktor.

Tabel 1. Efesiensi Pekerjaan Alat

\begin{tabular}{llccc}
\hline & Kondisi oprasi alat & Baik sekali & Baik & Pemeliharaan Mesin \\
& Sedang & Buruk \\
\hline Baik Sekali & 0.83 & 0.81 & 0.76 & 0.70 \\
Baik & 0.78 & 0.75 & 0.71 & 0.65 \\
Sedang & 0.72 & 0.69 & 0.65 & 0.60 \\
Buruk & 0.63 & 0.61 & 0.57 & 0.52 \\
\hline Suru
\end{tabular}

Sumber: Rochmanhadi (1985)

Dalam menetukan hasil yang berada pada tabel maka ada beberapa faktor yang menentukan hasil dari produktifitsa alat yang telah di tentukasn sebagai berikut:

1. Peralatan prima $=1.00-0.90$

2. Peralatan baik $=0.90-0.98$

3. Peralatan cukup $=0.80-0.70$

4. Peralatan sedang $=0.70-0.60$

\section{METODE}

\section{Pemeriksaan Keadaan Lapangan}

Dalam melakukan perencanaan pada pekerjaan, maka dilakukan observasi atau pengamatan di lapangan. Dalam melaksanakan suautu pengamatan harus mengetahui keadaan lapangan yang sebenarnya.

\section{Metode Pengumpulan Data}

Dalam malakukan pengumpulan data maka diperolah bahan - bahan yang tepat dan real/ nyata dan signifikan. Adapun metode pengumpulan data yang dipergunakan pada penelitian ini adalah:

\section{Data Primer}

Data primer merupakan data yang diperoleh dari pengamatan secara jelas dan real dilapangan, maupun mencari narasumber yang berada di lapanggan secara langsung kepada pelaksana kegiatan dilapangan

\section{Data Sekunder}

Data sekunder data yang diperoleh dari suatu instansi yang terkait dalam suatu kegiatan yang dilaksanakan dan data yang telah dilaksanakan penilitain oleh parah ahli dalam menemukan teori.

\section{Pengolahan Data}

Dalam suatu pengelolahan data, data yang terkumpul selanjutnya akan dilakukan penghitungan berdasarkan kinerja masing-masing alat dan banyaknya alat yang digunakan maka perhituungan yang akan dilakukan mengunakan rumus yang telah ditentukan dan akan disesuaikan dengan kondisi dilapangan.

\section{Diagram Alir Penelitian}


Fadhilah Akbar, Fakhrul Rozi Yamali dan Annisaa Dwiretnani, Analisa Pengunaan dan Produktivitas Alat Berat pada Kegiatan Peningkatan Ruas Jalan Simpang Pauh - Air Hitam Provinsi Jambi

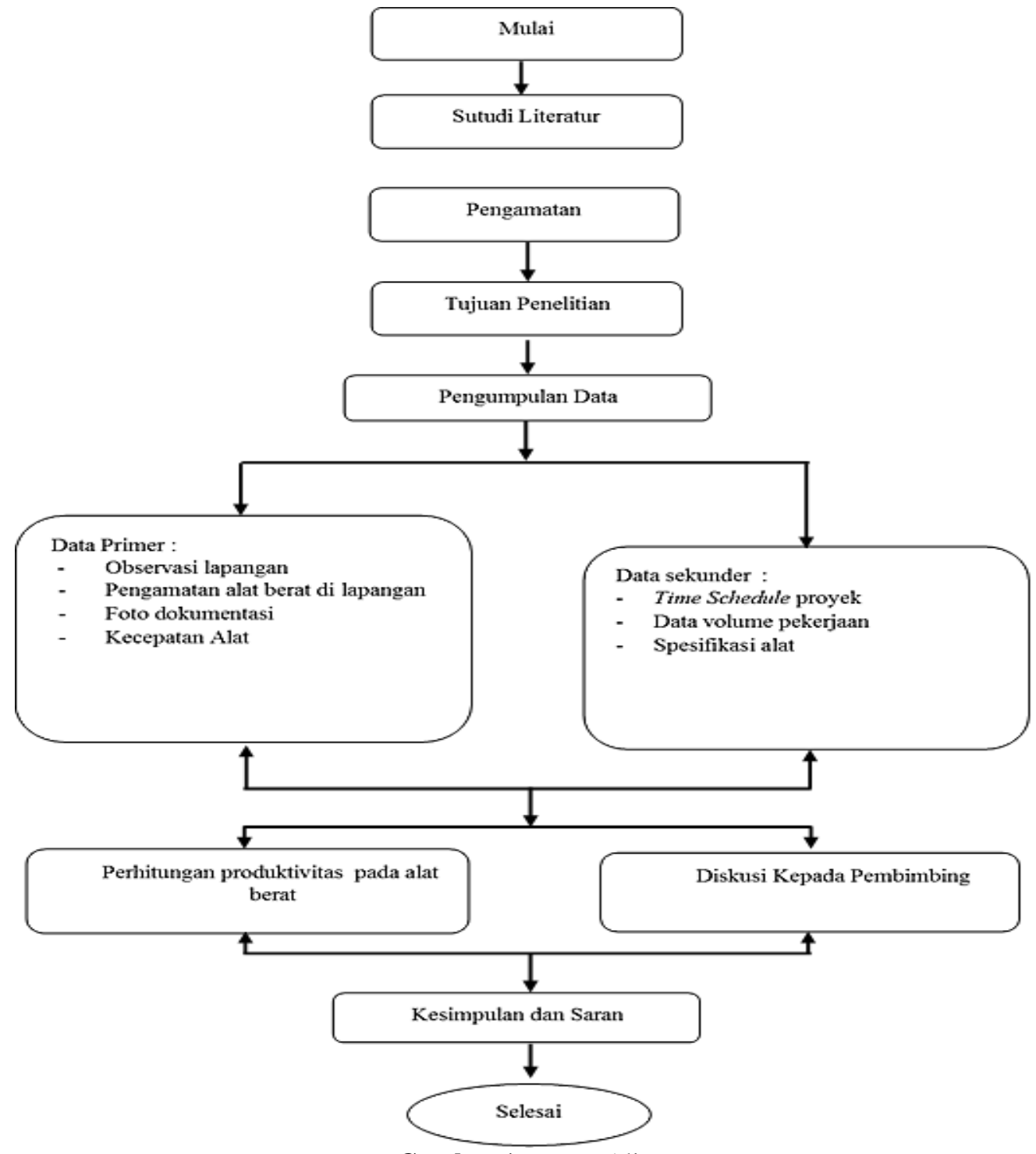

Sumber Data: Olahan (2020)

Gambar 1. Bagan Alir

\section{HASIL DAN PEMBAHASAN}

\section{Data Kegiatan Pekerjaan}

Pada pekerjaan perkerasan lentur laston lapis antar ( $\mathrm{AC}-\mathrm{BC}$ ) dengan panjang rencana awal pekerjaan sepanjang $2.235 \mathrm{~m}$. Dengan lebar pkerjaan sepanjang 4,5 $\mathrm{m}$ dan tebal recana $0,06 \mathrm{~m}$.

\section{Analisa Perhitungan Produktivitas Alat}

\section{Asphalt Finisher}

Makan perhitungan produksi alat asphalt finisher pada pekerjaan tersebut yang berfungsi sebagai alat penghampat material.

Merk dan type alat $=$ Mitsubishi Model Mf40w

Lebar screed $=3,5$ meter

Lebar efektif hampar alat berat $=2,25$ meter

Volume hopper $=9$ ton

Kecepatan operasi $(\mathrm{s})=3,0$ meter/detik

Tebal lapisan padat $(\mathrm{p})=0,06$ meter

Berat jenis aspal $(\mathrm{d} 1)=2,30$ ton

Efesiensi alat (e ) $=0,71($ tabel 2.1$)$

\section{Tandem Roller}

Untuk melakukan pekerjaan pemadata maka di butuhkan alat berat jenis Tandem roller. 
Fadhilah Akbar, Fakhrul Rozi Yamali dan Annisaa Dwiretnani, Analisa Pengunaan dan Produktivitas Alat Berat pada Kegiatan Peningkatan Ruas Jalan Simpang Pauh - Air Hitam Provinsi Jambi

Merk dan type alat $=$ Lutong Ltc

Lebar roda pengilas $=1,7$ meter

Berat roda depan \& belakang $=8$ ton

Kecepatan gerak alat $(\mathrm{s})=1,37 \mathrm{~km} / \mathrm{jam}$

Efesiensi kerja alat ( e ) $=0,71$ ( tabel 2.1 )

Jumlah lintasan $(\mathrm{n})=6$ lintasan

Tebal lapisan pemadatan $(\mathrm{p})=0,06$ meter

\section{Peneumatic Tried Roller}

Alat berat yang di gunakan untuk memperhyalus permukaan asphalt setelah di lakukan pemadatan pertama, makan digunakan alat berat jenis Peneumatic Tried Roller.

Merk dan type alat = Kawasaki Model Kr2Ow-2

Lebar efektif $(\mathrm{w})=$ lebar roller - lebar over lap

$\approx 2.00$ meter -0.30 meter

$\approx 1.70$ meter

Kecepatan gerak alat $(\mathrm{s})=4.06 \mathrm{~km} / \mathrm{jam}$

Efesiensi kerja alat $(\mathrm{e})=0.71$

Jumlah gerak bolak balik $(\mathrm{n})=18$

Tebal tebal pemadatan $(\mathrm{p})=0.06$ meter

Maka lama waktu pekerjaan yang di lakukan Pneumatic Tired Roller dalam kegiatan ini dapat dilihat dalam perhitungan sebagai berikut:

Tabel 2. Analisa Kapasitas Alat Pada Pekerjaan Perkerasan Lentur Lapis Antara (AC - BC)

\begin{tabular}{llll}
\hline No & Alat yang digunakan & Volume & Kapasitas kerja alat per-jam ( ton /jam) \\
\hline 1. & Asphalt finisher & 1450.04 ton & 39.68 ton / jam \\
2 & Tandem roller & 1450.04 ton & 38.03 ton / jam \\
3 & Pneumatic tired roller & 1450.04 ton & 37.56 ton / jam \\
\hline
\end{tabular}

Sumber: Data Olahan (2020)

Pada tabel diatas menujukan hasil yang di dapat pada kapsitas alat yang berkerja pada pekerjaan peningkatan ruas jalan simpang pauh - air hitam seperti berikut.

Tabel 3. Produktivitas Alat pada Pekerjaan Perkerasan lentur lapis antara (AC - BC)

\begin{tabular}{lllll}
\hline No & Alat yang digunakan & Kapasitas kerja alat per-jam ( ton /jam) & Waktu kerja alat per- hari & Lama kerja efektif \\
\hline 1. & Asphalt finisher & 39,68 ton / jam & 7 jam / hari & 6 hari \\
2 & Tandem roller & 38,03 ton / jam & 7 jam / hari & 6 hari \\
3 & Pneumatic tired roller & 37,56 ton / jam & 7 jam / hari & 6 hari \\
\hline
\end{tabular}

Sumber: Data Olahan (2020)

Pada tabel diatas menujukan hasil yang di dapat pada kapsitas alat yang berkerja pada pekerjaan peningkatan ruas jalan simpang pauh - air hitam seperti berikut.

\section{Perhitungan Perbandingan Produktivitas Alat Berat}

Untuk melakukan analisa produktivitas alat berat pada kegiatan peningkatan ruas jalan simpang pauh air hitam provinsi jambi ini maka dilakukan perhitungan ulang dengan melakukan perbandingan alat yang akan digunakan pada kegiataan peningkatan ruas jalan simpang pauh - air hitam dengan mengunakan alat berat tahun yang lebih muda dari sebelumnya ,agar dapat memproleh suatu kinerja yang lebih cepat dan efisien, maka perlu dilakukan perhitungan ulang untuk bahan perbandingan, maka harus dilakukan analisa atau perhitungan sebagai berikut:

\section{Asphalt Finisher}

Produktivitas alat asphalt finisher dengan specification seperti berikut:

Merk dan type alat $=$ VOLVO P2820D

Tahun alat $=2020$

Lebar width vb40 $=3.5$ meter

Lebar efektif hampar $(\mathrm{w})=2,25 \mathrm{~meter}$

Kapasitas hopper $(\mathrm{cp})=9$ ton 
Fadhilah Akbar, Fakhrul Rozi Yamali dan Annisaa Dwiretnani, Analisa Pengunaan dan Produktivitas Alat Berat pada Kegiatan Peningkatan Ruas Jalan Simpang Pauh - Air Hitam Provinsi Jambi

Kecepatan operasi $(\mathrm{s})=4,5 \mathrm{~km} / \mathrm{jam}$

Efesiensi kerja alat ( e ) $=0,83$ ( tabel 2.1)

Tebal lapisan padat $(p)=0,06$ meter

Suatu pekerjaan alat berat memeiliki waktu jeda, dalam proses peenghamparan material asphal alat berat biasanya memiliki waktu tunggu 5 - 15 menit, namun dalam pekerjaan simpang pauh - air hitam alat berat membutuhkan wktu 10 menit untuk penghamparan.

\section{Tandem Roller}

Perhitungan produktivitas alat tandem roller seperti berikut:

Merk dan type alat $=$ Volvo Dd105

Tahun alat $=2020$

Lebar roda pengilas $=1,68$ meter

Berat roller pengilas $=8$ ton

Kecepatan gerak alat $(\mathrm{s})=5,20 \mathrm{~km} / \mathrm{jam}$

Efesiensi kerja alat (e ) $=0,83$ (tabel 2.1)

Jumlah lintasan $(n)=6$ lintasan

\section{Peneumatic Tried Roller}

Perhitungan Produktivitas Alat Pneumatic Tried Roller seperti berikut:

Merk dan type alat $=$ Volvo Pt220

Tahun Alat $=2020$

Lebar Roller Pengilas $=1,98$ Meter

Lebar efektif $(\mathrm{W})=$ lebar roller - lebar over lap

$=1,98$ Meter $-0,25$ Meter

$=1,73$ Meter

Kecepatan gerak alat $(\mathrm{S})=7,50 \mathrm{~km} / \mathrm{Jam}$

Efesiensi kerja alat $(\mathrm{E})=0,83$ (Tabel 2.1)

Jumlah Gerak Bolak balik $(\mathrm{N})=18$

Tebal tebal pemadatan $(\mathrm{p})=0,06$ Meter

Tabel 4. Analisa Kapasitas Alat Baru Untuk Pekerjaan Perkerasan lentur lapis antara (AC - BC)

\begin{tabular}{llll}
\hline No & Alat yang digunakan & Volume & Kapasitas kerja alat per-jam ( ton /jam) \\
\hline 1. & Asphalt finisher & 1450,04 ton & 69,58 ton / jam \\
2 & Tandem roller & 1450,04 ton & 83,38 ton / jam \\
3 & Pneumatic tired roller & 1450,04 ton & 82,56 ton / jam \\
\hline
\end{tabular}

Sumber: Data Olahan (2020)

Pada tabel 4 Didapat kapasitas alat pada pekerjaan perkerasan lentur lapis antara (ac - bc) dengan alat asphalt finisher berkapasitas 69,58 ton / jam, untuk alat tandem roller berkapasitas 83,38 ton / jam, sedangkan pneumatic tired roller berkapasitas 82,56 ton / jam.

Tabel 5. Produktivitas Alat Baru Pada Pekerjaan Perkerasan lentur lapis antara (AC - BC)

\begin{tabular}{lllll}
\hline No & Alat yang digunakan & Kapasitas kerja alat per-jam ( ton /jam) & Waktu kerja alat per- hari & Lama kerja efektif \\
\hline 1. & Asphalt finisher & 69,58 ton / jam & 7 jam / hari & $3 \mathrm{hari}$ \\
2 & Tandem roller & 83,38 ton / jam & 7 jam / hari & $3 \mathrm{hari}$ \\
3 & Pneumatic tired roller & 82,56 ton / jam & 7 jam / hari & $3 \mathrm{hari}$ \\
\hline
\end{tabular}

Sumber :Data Olahan (2020)

Pada tabel 5. Produktivitas alat untuk pekerjaan perkerasan lentur lapis antara (ac - bc) dengan alat Asphalt Finisher, Tandem Roller, Pneumatic Tired Roller masing alat tersebut membutuhkan waktu kerja 7 jam/hari serta lama kerja efektif 3 hari.

\section{SIMPULAN}

Dari hasil pengamatan dan Analisa data maka dapat disimpulkan bahwa:

1. Produktivitas Asphalt Finisher Merk Mitsubishi MF40W didapat sebesar 39, 68 ton / jam dengan membutuhkan 1 unit alat untuk menghampar aspal dengan volume yang dibutuhkan sebanyak 1450,04 ton dalam waktu 6 hari 
Fadhilah Akbar, Fakhrul Rozi Yamali dan Annisaa Dwiretnani, Analisa Pengunaan dan Produktivitas Alat Berat pada Kegiatan Peningkatan Ruas Jalan Simpang Pauh - Air Hitam Provinsi Jambi

sedangkan, produktivitas Asphalt Finisher merk Vollvo P2820D Tahun 2020 didapat sebesar 69,58 ton / jam dengan membutuhkan 1 unit alat untuk menghampar aspal dengan volume yang dibutuhkan sebanyak 1450,04 ton dalam waktu 3 hari.

2. produktivitas Tandem Roller Lutong LTC didapat sebesar 38,03 ton / jam dengan membutuhkan 1 unit alat untuk pemadatan aspal dengan volume yang dibutuhkan sebanyak 1450,04 ton dalam waktu 6 hari sedangkan, produktivitas Tandem Roller Merk Vollvo DD 105 Tahun 2020 didapat sebesar 83,38 ton / jam dengan membutuhkan 1 unit alat untuk pemadatan aspal dengan volume yang dibutuhkan sebanyak 1450,04 ton dalam waktu 3 hari.

3. Produktivitas Pneumatic Tired Roler KR20W didapat sebesar 37, 56 ton / jam dengan membutuhkan 1 unit alat untuk memadatkan aspal dengan volume yang dibutuhkan sebanyak 1450,04 ton dalam waktu 6 hari sedangkan, produktivitas Pneumatic Tired Roller Merk Vollvo PT220 tahun 2020 didapat sebesar 82,56 ton / jam dengan membutuhkan 1 unit alat untuk memadatkan aspal dengan volume yang dibutuhkan sebanyak 1450,04 ton dalam waktu 3 hari.

\section{Saran}

Dari hasil perhitungan tersebut makan didapatkan kesimpulan tersebut, maka penyusunan ini dapat memberikan acuan atau pendoman bagi pekerja yang melaksanakan kegiatan bagi pihak terkait dalam kegiatan. Adapun saransaran tersebut antara lain:

1. Dari hasil perhitungan di atas maka dapat disimpulkan faktor produktitas alat baru lebih baik dibandingkan produktivitas alat yang ada dilapangan dikarenakan faktor alat yang digunakan meiliki tahun yang lebih baik di bandigkan dengan alat yang ada dilapang

2. Tetapi faktor alat yang ada dilapangan memiliki faktor produktifvitas yang sama dengan perhitungan waktu kerja yang ada di lapangan, tetapi alangkah lebih baiknya untuk kedepanya meperhitungakan produktivitas terlebih dahulu agar mendapatkan hasil yang baik dan efisien

3. Dalam memilih alat alangkah lebih baik mengunakan alat yang tahun lebih tepat agar dapat meminimalisir waktu kerja, agar pekerjaan berjalan secara baik.

4. Dalam pelaksanaan sebaiknya dalam proses pemeliharaan alat dilakukan secara efektif agar alat berat yang digunakan dapat berkerja dengan optimal

\section{DAFTAR PUSTAKA}

Alter F. R. Rambi 2018, Jermias Tjakra, Pingkan A.K Pratasis, Analisis Investasi Alat Berat Proyek Jalan Pt. Gading Murni Perkasa, dalam jurnal sipil statik, vol. 6 No. 11. hal. 887 - 894, ISSN 2237 - 6732.

Marzuki 2005, Metodologi Riset, Ekonsia,Yogyakarta.

Rostiyanti 1999, Produktivitas Alat Berat Pada Proyek Kontruksi, Penerbit Rineka Cipta, Jakarta.

Rostiyanti 2002, Fatena S, Alat Berat Untuk Proyek Konstruksi, penerbit Rineka Cipta, Jakarta.

Rostiyanti 2008, Manajemen Alat Berat untuk Proyek konstruksi, Penerbit Rineka Cipta, Jakarta.

Rochmanhadi 1985, Perhitungan Biaya Pelkasanaan Pekerjaan Dengan Mengunakan Alat - Alat Berat, Departemen Pekerjaan Umum, Jakarta.

Rochmanhadi 1992, Alat Berat dan pengunaannya, departemen pekerjaan umum, Jakarta.

Wilopo, Djoko 2011, Metode Konstruksi dan Alat - alat Berat, Fakultas Teknik Universitas Indonesia, Jakarta.

Wigroho, H.Y dan Suryadharma, H 1993, PTM (Pemindahan Tanah Mekanis) Bagian I. Universitas Atma Jaya Yogyakarta Dan Alat - Alat Berat. Penerbit Universitas Indonesia. Jakarta. 